\title{
Novel Nonsense Variants c.58C $>T$ (p.Q20X) and c.256G $>T$ (p.E85X) in the CHEK2 Gene Identified dentified in Breast Cancer Patients from Balochistan
}

\author{
Abdul Hameed Baloch ${ }^{1 *}$, Ahmad Nawaz Khosa ${ }^{1}$, Nasrullah Bangulzai ${ }^{1}$, Jamila \\ Shuja ${ }^{2}$, Hafiz Khush Naseeb ${ }^{2}$, Mohammad Jan', Illahi Bakhsh Marghazani ${ }^{1}$, \\ Masood-ul- Haq Kakar' ${ }^{1}$, Dost Mohammad Baloch ${ }^{1}$, Abdul Majeed Cheema ${ }^{3}$, \\ Jamil Ahmad $^{4}$
}

\begin{abstract}
Breast cancer is the most commonly occurring and leading cause of cancer deaths among women globally. Hereditary cases account 5-10\% of all the cases and CHEK2 is considered as a moderate penetrance breast cancer risk gene. CHEK2 plays a crucial role in response to DNA damage to promote cell cycle arrest and repair DNA damage or induce apoptosis. Our objective in the current study was to analyze mutations in the CHEK2 gene related to breast cancer in Balochistan. A total of 271 individuals including breast cancer patients and normal subjects were enrolled. All 14 exons of CHEK2 were amplified and sequenced. The majority of the patients $(>95 \%)$ had invasive ductal carcinomas (IDCs), $52.1 \%$ were diagnosed with tumor grade III and $56.1 \%$ and $27.5 \%$ were diagnosed with advance stages III and IV. Two novel nonsense variants i.e. $\operatorname{c.58C}>T$ (P.Q20X) and c.256G $>T$ (p.E85X) at exon 1 and 2 in two breast cancer patients were identified in the current study. Both the variants identified were novel and have not been reported elsewhere.
\end{abstract}

Keywords: Breast cancer - CHEK2 gene - novel nonsense variants - Balochistan

Asian Pac J Cancer Prev, 17 (3), 1089-1092

\section{Introduction}

Breast cancer is the most commonly occurring and one of the leading causes of death due to cancer among females worldwide accounting for $14-30 \%$ of all cancer deaths. Hereditary cases account $5-10 \%$ of the cases of which $15-20 \%$ are due to mutations in high penetrant breast cancer genes i.e. BRCA1 and BRCA2 (Willems PG, 2007; Panda S et al., 2008; Jemal et al., 2011; Baloch AH et al.,2014).

Germline mutations in other genes like CHEK2, ATM, BR1P1, PABL2, CHEK2 and others have also been proposed to be causes of the breast cancer (MeijersHeijboer et al., 2002; Renwick et el., 2006; Seal et al., 2006; Rahman et al., 2007). CHEK2 considered as a moderate penetrance breast cancer as well as other cancers risk gene (Vahteristo et al., 2002; Oldenburg et al., 2003; Dong et al., 2003; Cybulski et al; 2004; Nevanlinna H, 2006 and Walsh T et al., 2011) and play a crucial role in response to DNA damage, phosphorilating BRCA1, p53, CDC25C and CDC25A to either promote cell cycle arrest and repair the DNA damage or induce apoptosis ( Zeng etal., 1998; Lee et al., 2000; Chehab NH, 2000; Falck et al., 2001; Meijers et al., 2002). Cell-cycle checkpoints are activated in respose to DNA damage to restrain cell proliferation.

Gene CHEK2 encodes a serine/threonine kinase, phosphorylated by Ataxi Telangectasia Mutated (ATM) at G2 checkpoint, and is activated in the nucleus of the cell in response to DNA double strand damage (Matsuoka et al., 2000; Bartek et al., 2003). Various sporadic and hereditary cancers in human are reported to be caused by mutations in gene CHEK2 (Meijers-Heijboer et al., 2002; Chaturvedi et al., 1999; Matsouka et al., 2000; Ingvarsson et al., 2002; Craig and Hupp, 2004; Bartek, Hollestelle et al., 2010 and Lukas, 2003 and Nevanlinna and Bartek, 2006). CHEK2 1100delC most widely been study and suggested to increase the risk of breast cancer in women who have a positive family history of breast cancer, however this mutation has not been reported in Asian populations (Wu et al., 2001; Weischer et al., 2008; Fletcher et al., 2009; Baloch et al., 2014). Different missense mutations other

${ }^{1}$ Faculty of Veterinary and Animal Sciences, Lasbela University of Agriculture, Water and Marine Sciences Uthal, ${ }^{2}$ Center for Nuclear Medicine and Radiotherapy (CENAR), ${ }^{4}$ Department of Biotechnology, Balochistan University of Information Technology, Engineering and Management Sciences (BUITEMS), Quetta, ${ }^{3}$ Institute of Molecular Biology and Biotechnology, The University of Lahore, Pakistan*For correspondence: hameedbaloch77@yahoo.com 
than 1100delC may lead to loss of function and cause cancer (Narod, 2010 and Le Calviz-Kem et al., 2011).

Our objective in this study was to analyze mutations in gene CHEK2 related to breast cancer. This study was conducted in Balochistan, Pakistan on 171 breast cancer patients and 100 normal subjects. Consent forms were obtained from all the subjects. Venous blood $(3 \mathrm{ml})$ was drawn for DNA extraction from each individual. All 14 exons and exon intron boundaries of gene CHEK2 were amplified and sequenced by using synthesized exon specific primers. We identified two nonsense variants i.e. c.58C $>$ T (P.Q20X ) and c.256G > T (p.E85X) at exon 1 and 2 in two breast cancer patients. To the best of our knowledge these mutations are novel as they have not been identified elsewhere. The study was approved from Institutional Review Board (IRB) of Balochistan University of Information Technology, Engineering and Management Sciences (BUITEMS), Quetta.

\section{Materials and Methods}

Current study was performed on 171 breast cancer patients and 100 normal subjects. Informed consents were obtained from all the volunteers (breast cancer patients and normal subjects). History of the disease was taken from all the breast cancer patients. Intravenous blood samples (3ml) were collected and dispensed into $15 \mathrm{ml}$ falcon tubes containing EDTA to avoid clotting of blood samples. The samples were kept frozen at $-20^{\circ} \mathrm{C}$ for 24 hours prior to further processing. DNA was isolated through an inorganic standard method already published. Primers were designed for all fourteen exons including exon-intron boundaries of gene CHEK 2 using Primer 3 software and synthesized. All the exons were amplified and sequenced using Big Dye Terminator Chemistry on an automated 3100 ABI prism DNA sequencer. The sequences results were checked and compared with the normal sequences using genome browser of ENSEMBL.

\section{Results}

A total of 271 subjects including 171 breast cancer patients and 100 normal subjects were enrolled in current study, belonging to different ethnic groups of Balochistan. Ethnic groups with high number of patients effected with breast cancer were; Pashtoon ethnic group with $31.6 \%$, Afghani with $25.1 \%$ patients and $22.8 \%$ patients from Baloch ethnic group. Majority of the patients (>95\%) were effected with invasive ductal carcinoma (IDC) including $52.05 \%$ of the total patients were diagnosed with tumor grade III. Age is one of the major risk factor of breast cancer and in current study $>43 \%$ patients were from the age group 41-50 years followed by $26.9 \%$ were from age group 31-40 years.

Other features of the disease were noticed in current study were; $35.7 \%$ patients at the time of diagnosis were overweight and $15.2 \%$ were obese, $56.14 \%$ and $27.49 \%$ patients were diagnosed with advance stages III and IV consecutively. Hormonal receptor status of 49 patients was available in their clinical reports out of which $16.4 \%$ patients were with oestrogen and progesterone receptors
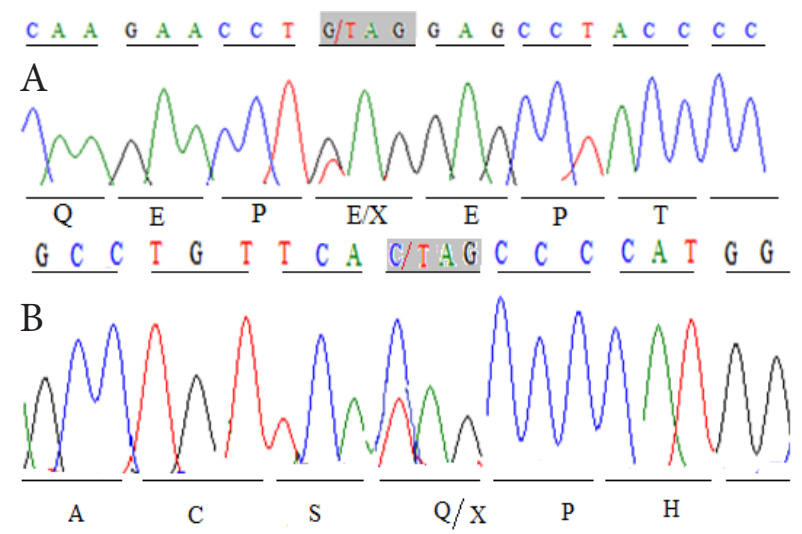

Figure 1. a) c.256G > T(p.E85X) Heterozygous; b) c.58G $>$ T(p.Q20X) Heterozygous

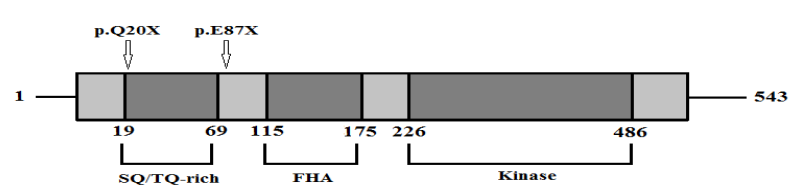

Figure 2. Functional Domains of CHEK2 Protein

(ERPR) positive status. Infertility was reported in $8.2 \%$ patients.

The two nonsense variants c.58C $>\mathrm{T}$ (p.Q20X) (Fig.1a) reported in a patient from Baloch ethnic group diagnosed with breast cancer IDC type at the age of 55 years with tumor grade III and c.256G $>$ T (p.E85X) (Fig. 1b) observed in a patient with IDC from Pashtoon ethnic group at the age of 45 years with tumor grade III. To the best of our knowledge both the mutations were novel and have not been reported or published before anywhere else.

\section{Discussion}

Breast cancer is a global burden occurring most commonly and suggested to be the second foremost cause of death among women worldwide. About one million new breast cancer cases each year, 55\% death cases and $45 \%$ diagnosed cases are reported to be from middle and low income countries (Hortobagyi et al., 2005; Curado et al., 2007; Globocan, 2012). Our aim in this study was to investigate gene CHEK2 mutations related to breast cancer from Balochistani population. For this purpose we identified 248 breast cancer patients from different ethnic groups of Balochistan. Out of 248 breast cancer patients 171 agreed to take part in current study as volunteers who were than enrolled after signing the consent forms. 100 normal individuals were also enrolled in this study. The occurrence and severity of breast cancer among different ethnic groups with diverse lifestyle is varying. Multiple risk factors like lake of awareness, lack of health facilities, lifestyle and genetic factors make certain ethnic groups more prone to breast cancer (Ries et al., 2003; Rowan et al., 2009; Chelbowsky et al., 2009). We identified majority of the patients from Pashtoon ethnic group including 31.6\% local Pashtoons of Balochistan and $25.1 \%$ Afghan origin Pashtoon (in majority), Hazara and Uzbak ethnic groups. Baloch ethnic group constituting majority of the population of Balochistan, 22.8\% of the 
total patients identified were from Baloch ethnic group. Studies suggest that genetic back ground or ethnicity is a crucial risk factor with varying degree among different ethnic population for females globally to be affected with breast cancer (Ries et al., 2003, BCERF, Fact sheet No. 47, 2003 and Rowan et al., 2009). Afghani ethnic group constituting $25.1 \%$ of the total patients in current study were Afghani (Afghan refugees) from Afghanistan. In a study conducted in Pakistan in 2007 indicates that the risk of breast cancer in migrant ethnicities both Indian and Afghani, was slightly higher (Burgri et al., 2007). It is suggested that the variations in the incidence of breast cancer and survival of it is almost based on environmental and cultural effects rather than genetic differences and lack of awareness increase the chances to certain ethnic groups be affected with higher grade and advance stage of breast cancer (BCERF, Fact sheet No. 47, 2003 and Forbe et al., 2009). Similarly Gathani et al., in their study suggest that the occurrence of breast cancer among different ethnic groups is almost due to variations in known risk factors of the disease (Gathani T et al., 2014). IDC was the most commonly occurring breast cancer, in current study $>95 \%$ patients were diagnosed with IDC type of breast cancer. Studies suggest that IDC is the commonest diagnosed type of breast cancer, constitute for $>80 \%$ of all the breast cancer cases (Meijers-Heijboer et al., 2002; Cristofanilli M et al., 2005; Ludwig, 2008; Baloch AH et al., 2012; Baloch AH et al, 2013). Other features observed in current study were; majority of the patients $(56.14 \%$ and $27.49 \%$ ) with advance stages (III and IV) of breast cancer and the average age was 46.19 years. The two nonsense variations observed were novels falling at SQ/TQ domain of the CHEK2 kinase (Figure 2) resulting the synthesis of an immature protein. CHEK2 gene response to DNA damage and play a vital role in DNA repair mechanism, germline mutations in CHEK2 gene have been reported to increase the occurrence of breast cancer in patients negative with BRCA1 mutation (Desrichard et al., 2011; Mohamad et al., 2015). Studies suggest that germline variations in gene CHEK2 are diversified among different ethnic groups especially in patients negative for BRCAs (Meijers et al., 2002; Desrichard et al., 2011; Kuusisto et al., 2011). Our aim in current study was to analyze mutations in gene CHEK2 related with breast cancer, for this purpose we sequenced all fourteen exons including exon intron boundaries of gene CHEK2, our results revealed two nonsense variants which were novel, as they have not been reported or published elsewhere. Both the variants identified in cases and not diagnosed in any other case and control samples. Certain nonsense mutations in gene CHEK2 have also been identified and suggested that these variations result the synthesis of a premature protein with lack of function by affecting the domains of resulting protein. These types of mutations have also been reported to show resistant to therapies by different drugs (Staalesen et al., 2004; Chrisanthar et al., 2008).

In conclusion, Breast cancer is the most commonly occurring cancer among women globally. Gene CHEK2 plays a pivotal role in response to DNA damage and is suggested to increase the risk of breast cancer 3 fold in familial breast cancer cases negative for BRCA1 and
BRCA2 mutations. The two nonsense variants identified in current study are concluded to be rare and may not to be associated with genetic predisposition of breast cancer in Balochistani population as both the variants were not observed in any other breast cancer cases and control investigated in current study

\section{Acknowledgements}

We highly acknowledge all the patients and the normal subjects who took part as volunteers in the study. We acknowledge International Agency for Research on Cancer (IARC) for supporting us through research grant (CRT No. Fel/11/01). Many thanks to Balochistan University of Information Technology, Engineering and Management Sciences (BUITEMS) and Center for Nuclear Medicines and Radiotherapy (CENAR), Quetta that facilitated and made this research work possible

\section{References}

Willems PG (2007) Susceptibility genes in breast cancer: more is less? Clin Genet. 72, 493-6.

Panda S, Isbatan A, Adami GR (2008) Modification of the ATM/ ATR directed DNA damage response state with aging and long after hepatocyte senescence induction in vivo. Mech Ageing Dev, 129, 332-40.

Jemal A, Bray F, Center MM, et al (2011) Global cancer statistics. CA Cancer J Clin, 61, 69-90.

Baloch AH, Daud S, Raheem N, et al (2014). Missense mutations (p.H371Y, p.D438Y) in gene CHEK2 are associated with breast cancer risk in women of Balochistan origin. Mol Biol Rep, 41,1103-7.

Meijers-Heijboer H, van den Ouweland A, Klijn J, et al (2002) CHEK2-breast cancer consortium: low-penetrance susceptibility to breast cancer due to CHEK $2 * 1100 \mathrm{delC}$ in noncarriers of BRCA1 or BRCA2 mutations. Nat Genet, 31, 55-59.

Renwick A, Thompson D, Seal S, et al (2006). Breast Cancer Susceptibility Collaboration (UK), Easton DF, Stratton MR, Rahman N: ATM mutations that cause ataxia-telangiectasia are breast cancer susceptibility alleles. Nat Genet, 38, 873-5.

Seal S, Thompson D, Renwick A, et al (2006). Truncating mutations in the Fanconi anemia J gene BRIP1 are lowpenetrance breast cancer susceptibility alleles. Nat Genet. 38, 1239-41.

Rahman N, Seal S, Thompson D, et al (2007). Breast Cancer Susceptibility Collaboration (UK), Easton DF, Stratton MR: PALB2, which encodes a BRCA2-interacting protein, is a breast cancer susceptibility gene. Nat Genet.39, 165-7.

Vahteristo P, Bartkova J, Eerola H, et al (2002). A CHEK2 genetic variant contributing to a substantial fraction of familial breast cancer. Am J Hum Genet. 71,432-8.

Oldenburg RA, Kroeze-Jansema K, Kraan J, et al (2003). The CHEK2*1100delC variant acts as a breast cancer risk modifier in non-BRCA1/BRCA2 multiple-case families. Cancer Res, 63, 8153-7.

Dong X, Wang L, Taniguchi K, et al (2003). Mutations in CHEK2 associated with prostate cancer risk. Am J Hum Genet, 72, 270-80.

Cybulski C, Gorski B, Huzarski T, et al (2004) CHEK2 is a multiorgan cancer susceptibility gene. Am J Hum Genet, 75, 1131-5.

Nevanlinna H, Bartek J (2006) The CHEK2 gene and inherited breast cancer susceptibility. Oncogene, 25, 5912-9. 


\section{Abdul Hameed Baloch et al}

Walsh T, Casadei S, Lee MK, et al (2011). Mutations in 12 genes for inherited ovarian, fallopian tube, and peritoneal carcinoma identified by massively parallel sequencing. Proc Natl Acad Sci USA, 108, 18032-7.

Zeng Y, Forbes KC, Wu Z, et al (1998). Replication checkpoint requires phosphorylation of the phosphatase $\mathrm{Cdc} 25$ by $\mathrm{Cds} 1$ or Chk1. Nature, 395, 507-10.

Lee JS, Collins KM, Brown AL, Lee CH, Chung JH (2000). hCds1-mediated phosphorylation of BRCA1 regulates the DNA damage response. Nature. 404, 201-04.

Chehab NH, Malikzay A, Appel M, Halazonetis TD (2000). Chk2/hCds1 functions as a DNA damage checkpoint in $\mathrm{G}(1)$ by stabilizing p53. Genes Dev, 14, 278-288.

Falck J, Mailand N, Syljuasen RG, et al (2001). The ATM-Chk2Cdc25A checkpoint pathway guards against radioresistant DNA synthesis. Nature, 410, 842-7.

Matsuoka S, Rotman G, Ogawa A, et al (2000). Ataxia telangiectasia-mutated phosphorylates Chk2 in vivo and in vitro. Proc Natl Acad Sci USA, 97, 10389-94.

Bartek J, Lukas J (2003). Chk1 and Chk2 kinases in checkpoint control and cancer. Cancer Cell, 3, 421-9.

Wu X, Webster SR and Chen J (2001). Characterization of tumorassociated chk2 mutations. J Biol Chem, 276, 2971-74.

Weischer M, Bojesen SE, Ellervik C, et al (2008). CHEK2_1100delC genotyping for clinical assessment of breast risk: meta analysis of 26,000 patient cases and 27,000 control. J Clin Oncol, 26, 542-8.

Fletcher O, Johnson N, Dos Santos Silva I, et al (2009). Family history, genetic testing, and clinical risk prediction: pooled analysis of CHEK2 1100delC in 1,828 bilateral breast cancers and 7,030 controls. Cancer Epidemiol Biomarkers Prev, 18, 230-4.

Narod SA (2010) Testing for CHEK2 in the cancer genetics clinic: ready for prime time? Clin Genet, 78, 1-7.

Le Calvez-Kelm F, Lesueur F, Damiola F, et al (2011). Rare, evolutionarily unlikely missense substitutions in CHEK2 contribute to breast cancer susceptibility: results from a breast cancer family registry case-control mutationscreening study. Breast Cancer Res, 13, 6 .

Available online: Globocan (2012). http://globocan.iarc.fr/ Default.aspx.

Curado MP, Edwards B, Shin HR, et al (2007)\ eds. Cancer incidence in five continents. Vol. IX. Lyon, France: International Agency for Research on Cancer, 2007. (IARC scientific publications no. 160.) (Accessed December 27, 2007, at http://www-dep.iarc.fr/.)

Hortobagyi GN, de la Garza Salazar J, Pritchard K, et al (2005). ABREAST investigators: the global breast cancer burden: variations in epidemiology and survival. Clin Breast Cancer. 6, 391-401

Ries LAG, Eisner MP, Kosary CL (2003) Cancer Statistics Review, 1975-2000. Bethesda, MD. National Cancer Institute.

Rowan T. Chlebowski, Lewis H, et al (2009). Breast Cancer after Use of Estrogen plus Progestin in Postmenopausal Women. N Engl J Med, 360, 573-587.

Chlebowski RT, Kuller LH, Prentice RL, et al (2009). Breast cancer after use of estrogen plus progestin in postmenopausal women. N Engl J Med, 360, 573-87.

Gathani T, Ali R, Balkwill A, et al (2014) Ethnic differences in breast cancer incidence in England are due to differences in known risk factors for the disease: prospective study. $\mathrm{Br} \mathrm{J}$ Cancer, 110, 224-229.

Meijers-Heijboer H, van den Ouweland A, Klijn J, et al (2002). CHEK2-breast cancer consortium. low-penetrance susceptibility to breast cancer due to CHEK $2 * 1100 \mathrm{delC}$ in noncarriers of BRCA1 or BRCA2 mutations. Nat Genet
31, 55-9.

Cristofanilli M, Gonzalez-Angulo A, Sneige N, et al (2005) Invasive lobular carcinoma classic type: response to primary chemotherapy and survival outcomes. J Clin Oncol, 23, 41-8.

Ludwig J (2008) Personalized therapy of sarcomas: integration of biomarkers for improved diagnosis, prognosis, and therapy Sselection. Curr Oncol Rep. 10, 329-37.

Baloch A.H, Shuja J, Daud S, et al (2013) Various aspects, patterns and risk factors in breast cancer patients of balochistan. Asian Pac J Cancer Prev, 13, 4013-6.

Desrichard A., Bidet Y, Uhrhammaer N and Bignon Yves-J (2011). CHEK2 contribution to hereditary breast cancer in non-BRCA families. Breast Cancer Res, 13, 119

Mohamad S, Nurismah Md Isa1 N, Muhammad R, et al (2015). Prevalence of CHEK2 gene mutations in multiethniccohorts of breast cancer patients in Malaysia. PLoS ONE, 10, 117104.

Kuusisto KM, Bebel A, Vihinen M, et al (2011) Screening for BRCA1, BRCA2, CHEK2, PALB2, BRIP1, RAD50, and CDH1 mutations in high-risk Finnish BRCA1/2-founder mutation negative breast and/or ovarian cancer individuals. Breast Cancer Res, 13, 20.

Staalesen V, Falck J, Geisler S, et al (2004). Alternative splicing and mutation status of CHEK2 in stage III breast cancer. Oncogene, 23, 8535-44.

Chrisanthar R, Knappskog S, Lokkevik E, et al (2008). CHEK2 Mutations affecting kinase activity together with mutations in tp53indicate a functional pathway associated with resistance to epirubicin in primary breast cancer. PLoS ONE, 3, 3062. 